\title{
Effects of Greek economic crisis on health are real
}

\author{
Alexander Kentikelenis research fellow ${ }^{1}$, Marina Karanikolos research fellow ${ }^{2}$, Irene Papanicolas \\ lecturer in health economics ${ }^{3}$, Sanjay Basu assistant professor of medicine ${ }^{4}$, Martin McKee professor \\ of European public health ${ }^{2}$, David Stuckler lecturer in sociology ${ }^{5}$
}

${ }^{1}$ Harvard University, Cambridge, MA, USA; ${ }^{2}$ Department of Public Health and Policy, London School of Hygiene and Tropical Medicine, London, UK; ${ }^{3}$ Department of Social Policy, LSE Health, London School of Economics and Political Science, London, UK; ${ }^{4}$ Stanford Prevention Research Center, Stanford University, Palo Alto, CA, USA; ${ }^{5}$ Department of Sociology, University of Cambridge, Cambridge CB2 3RQ, UK

We were surprised by Liaropoulos's conclusions about the health effects of the Greek economic crisis. ${ }^{1}$ His article contains several unreferenced assertions and contradictions, such as statements that there is "no evidence of denial of services to patients" yet "many [people] are without cover" and the church, non-governmental associations, and others are "rallying to help." He suggests that our peer reviewed research published in the Lancet, which reported evidence of a Greek health crisis, used dated information. ${ }^{2}$ In fact, it used the most up to date data at the time, which were collected two years into the crisis. The health effects have been confirmed by Greek academics using 2011 data. ${ }^{3}$ His claim of "no evidence that [the economic crisis] has affected health" is at odds with the doubling in the prevalence of depression, ${ }^{4}$ while Eurostat data also show dramatic increases in unmet medical need and infant mortality. Nor does he refer to the 2011 reports of increased infectious diseases, such as the large rise in HIV among injecting drug users, associated with budget cuts including closure of needle exchange services, ${ }^{5}$ or the re-emergence of malaria (for the first time since 1974) associated with cuts to mosquito spraying in the south of the country. Liaropoulos dismisses some evidence of harm as "anecdotal" but fails to mention that investigative journalists had to fill the gap left by the European authorities failure to monitor the full health effects of the measures they are imposing. We do not dispute that the Greek health system has long needed reforming, but reform should be informed by data on the health needs of the population.

Competing interests: None declared.

Liaropoulos L. Greek economic crisis: not a tragedy for health. BMJ 2012;345:e7988. (27 November.)

2 Kentikelenis A, Karanikolos M, Papanicolas I, Basu S, McKee M, Stuckler D. Health effects of financial crisis: omens of a Greek tragedy. Lancet 2011;378:1457-8.

3 Zavras D, Tsiantou V, Pavi E, Mylona K, Kyriopoulous J. Impact of economic crisis and other demographic and socio-economic factors on self-rated health in Greece. Eur $J$ Public Health 2012 [forthcoming].

4 Economou M, Medianos M, Peppou LE, Patelakis A, Stefanis CN. Major depression in the era of economic crisis: a replication of a cross-sectional study across Greece. J Affect Disord 2012; published online 29 Aug.

5 Fotiou A, Micha K, Paraskevis D, Terzidou M, Malliori MM, Hatzakis A. HIV outbreak among injecting drug users in Greece: an updated report for the EMCDDA on the recent outbreak of HIV infections among drug injectors in Greece. European Monitoring Centre for Drugs and Drug Addiction, 2012.

Cite this as: BMJ 2012;345:e8602

๑ BMJ Publishing Group Ltd 2012 